\title{
Ultrasonido y pulmón
}

\section{Lung Ultrasound}

\author{
María Carolina Cabrera Schulmeyer ${ }^{1}$
}

\section{Examen ultrasonográfico normal}

U n tema que ha sido de gran controversia es el uso de ultrasonido (US) para evaluar el parénquima pulmonar[1]. Se discute, ya que tanto el hueso como el aire son pésimos conductores de los ecos emitidos con el transductor. Esta situación se ha solucionado estudiando los artefactos que se generan con el NO paso de los ecos. Una vez conocidos los artefactos se hace fácil su interpretación.

Tradicionalmente, el abordaje diagnóstico por la imagen del tórax en el paciente se ha basado en la radiografía simple anteroposterior. Sin embargo, ésta presenta grandes limitaciones en la precisión diagnóstica de la enfermedad pleuropulmonar. La introducción de la tomografía axial computarizada resolvió en gran medida este problema, pero con el doble inconveniente de las dosis de radiación y del inevitable traslado fuera de la unidad de hospitalización[2]. En este contexto, la ecografía pulmonar, gracias a su portabilidad, se convierte en una técnica útil a la cabecera del paciente y fácilmente reproducible y sin radiaciones ionizantes[3].

En la ecografía pulmonar, las costillas, el aire del pulmón actúan como barreras para los ultrasonidos y provocan artefactos que debemos reconocer e interpretar para un correcto diagnóstico. El ultrasonido pulmonar se ha ido desarrollando progresivamente tanto en sus aspectos conceptuales como de aplicación práctica a la cabecera de los pacientes[4],[5].

El equipo de ecografía necesario para la realización de la técnica solo precisa de imagen bidimen- sional y en modo $M$, pero actualmente casi todos los equipos modernos están dotados de otras posibilidades (doppler, color, armónicos, etc.). Más importante es la disponibilidad de sondas multifrecuencia o de varios tipos de sonda. Las sondas de frecuencias entre 3,5-5 MHz, utilizadas para la exploración abdominal y cardiaca, proporcionan una adecuada visualización de los planos profundos, y permiten la caracterización de las consolidaciones y el derrame pleural. Para las estructuras más superficiales, es decir, la pleura los signos y los artefactos que se generan de ella, los transductores lineales de frecuencia superior a $5 \mathrm{MHz}$ proporcionan mucha mejor resolución. La forma de la sonda utilizada (lineal, convexa o sectorial) también dependerá de la zona a estudiar, y será convexa si el espacio intercostal es estrecho, para evitar la interferencia acústica que producen las costillas (Figura 1).

Los transductores sectoriales son adecuados para el examen del espacio pleural por vía intercostal directa, ya que presenta una visión muy estrecha en los campos cercanos y el espacio pleural se identifica por los artefactos.

En los pacientes la exploración se realiza en la posición de decúbito supino, que permite un fácil abordaje anterolateral. Son suficientes 4 áreas en cada hemitórax, y que lo dividen en 2 zonas, anterior y lateral, con la línea axilar anterior como divisoria. A su vez, cada zona se divide en una superior y otra inferior según una línea horizontal que atravesaría la unión del tercio medio con el inferior del esternón. La exploración comenzaría por la zona anterosuperior y acabaría por la lateroinferior, con cortes longitudinales y transver-

Universidad de Valparaíso, sede Hospital FACH.

Fecha de recepción: 10 de enero de 2019

Fecha de aceptación: 05 de marzo de 2019

\section{ORCID}

https://orcid.org/0000-0002-6105-5780

Correspondencia:

María Carolina Cabrera Schulmeyer

Email: maria.cabrera@uv.cl 


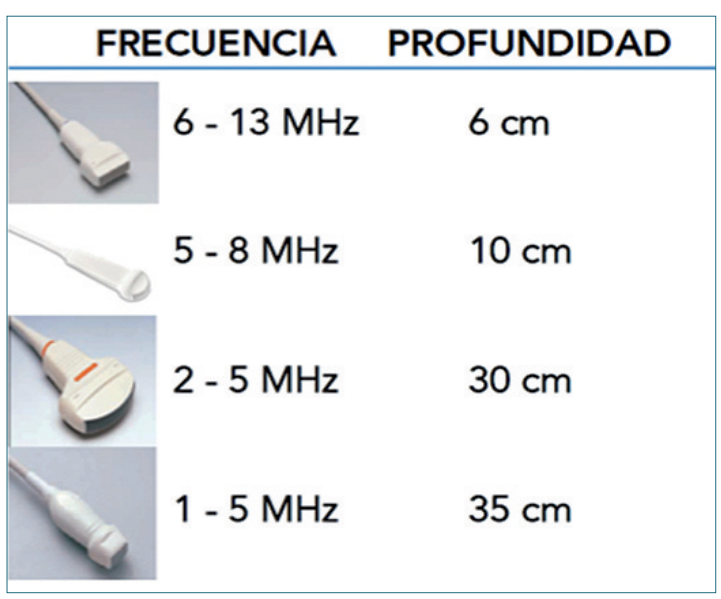

Figura 1. Tipos de sonda para realizar US pulmonar.

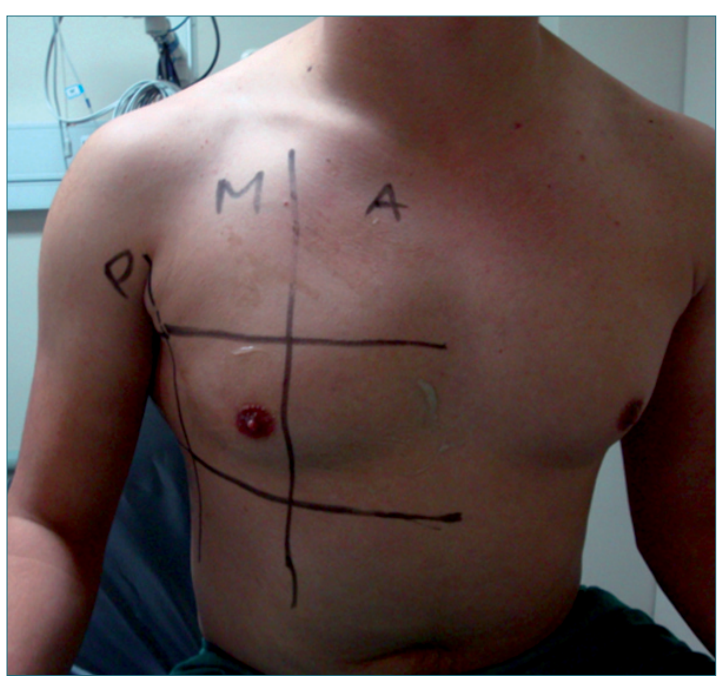

Figura 3. División del tórax en cuadrantes en pacientes sentados.

sales. A veces es necesario el estudio de las zonas dorsales, para lo que es precisa una ligera inclinación del enfermo, que se logra exclusivamente con una leve aducción del brazo ipsolateral (Figuras 2 y 3).

\section{Examen normal}

Al situar el transductor lineal en sentido longitudinal perpendicular a los espacios intercostales se visualizan cerca de los bordes laterales de la pantalla 2 interfases ecogénicas redondeadas con una marcada sombra acústica que corresponde a las costillas.

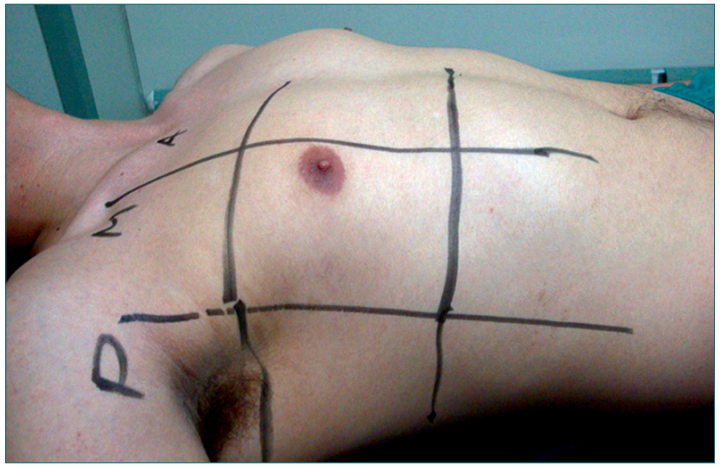

Figura 2. División del tórax en cuadrantes.

Aproximadamente a medio centímetro por debajo del inicio de éstas se sitúa una línea hiperecogénica horizontal que representa la pleura[6]. Con transductores de alta frecuencia y gran resolución a poca profundidad se pueden observar las 2 capas: parietal y pleural, de unos $2 \mathrm{~mm}$ de anchura y de aspecto regular, separadas entre sí por el espacio pleural (0,3 mm). En conjunto, el borde superior de las sombras de las costillas y la línea pleural componen una imagen que semeja el perfil de un murciélago y, por esto, ha recibido la denominación signo del murciélago (Figura 4).

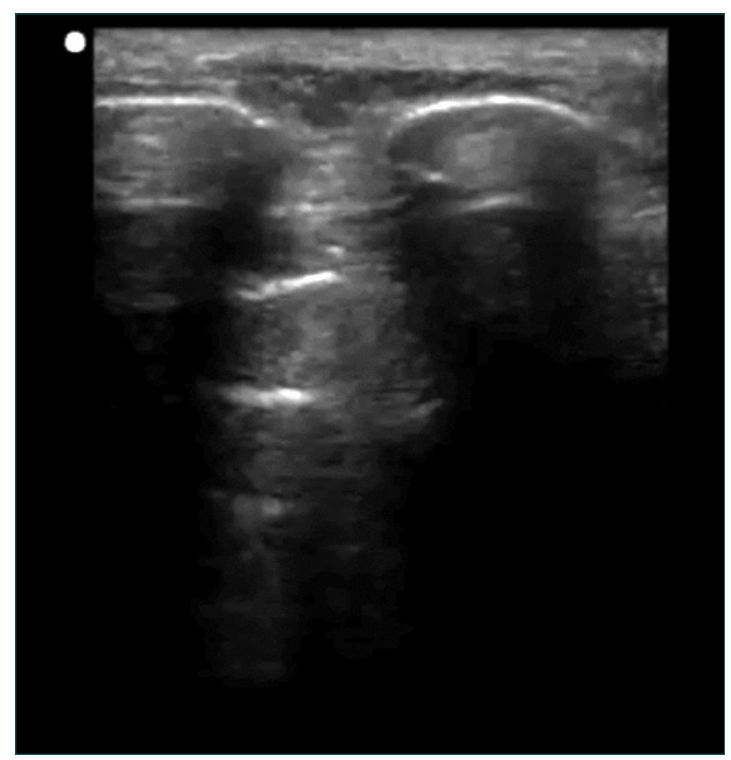

Figura 4. Imagen de pulmón normal. La línea superior hiperrefringente corresponde a la pleura y las líneas paralelas equidistantes corresponden a las líneas A 8, se denomina imagen del murciélago). 

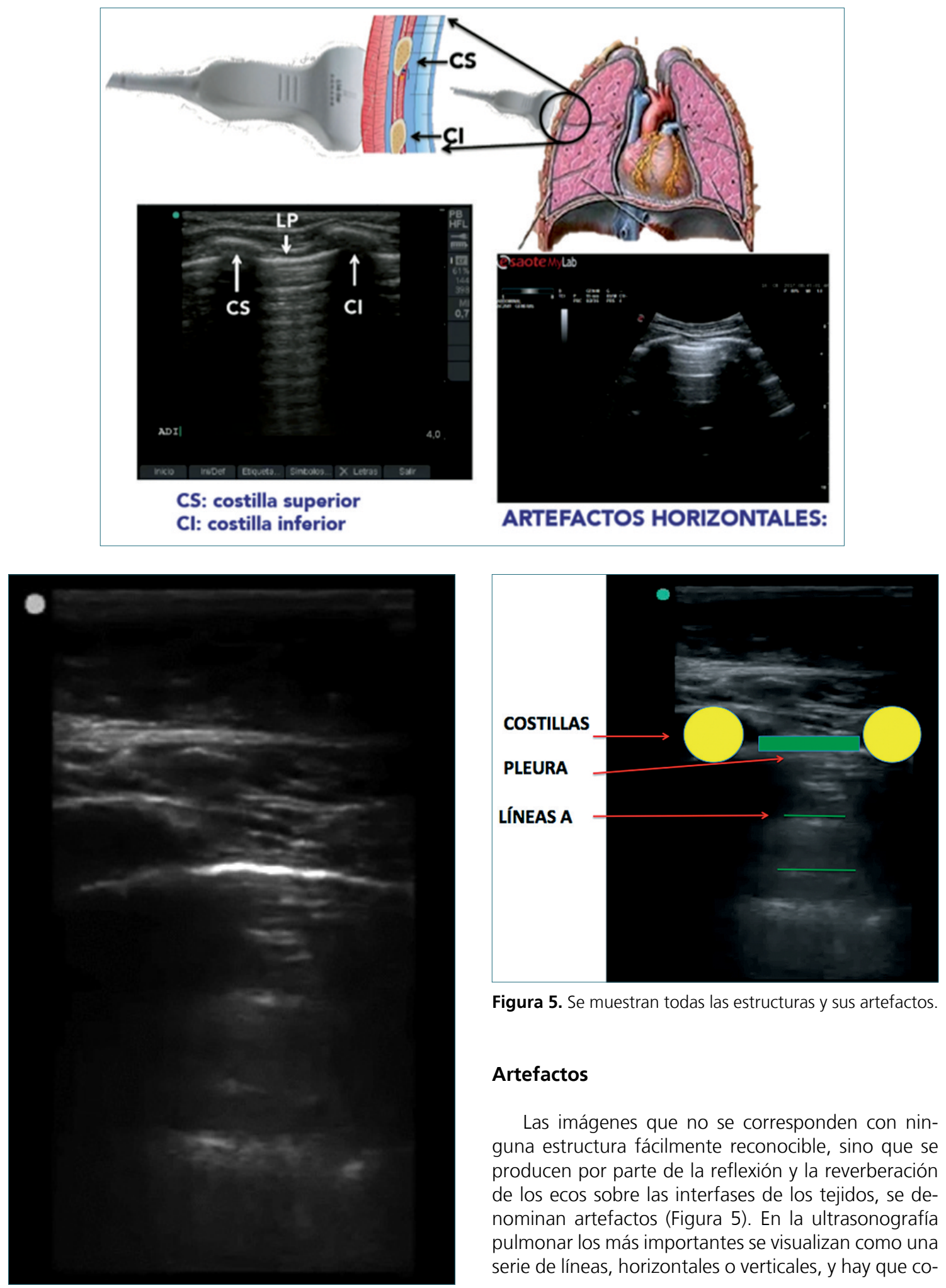

Figura 5. Se muestran todas las estructuras y sus artefactos.

\section{Artefactos}

Las imágenes que no se corresponden con ninguna estructura fácilmente reconocible, sino que se producen por parte de la reflexión y la reverberación de los ecos sobre las interfases de los tejidos, se denominan artefactos (Figura 5). En la ultrasonografía pulmonar los más importantes se visualizan como una serie de líneas, horizontales o verticales, y hay que co- 


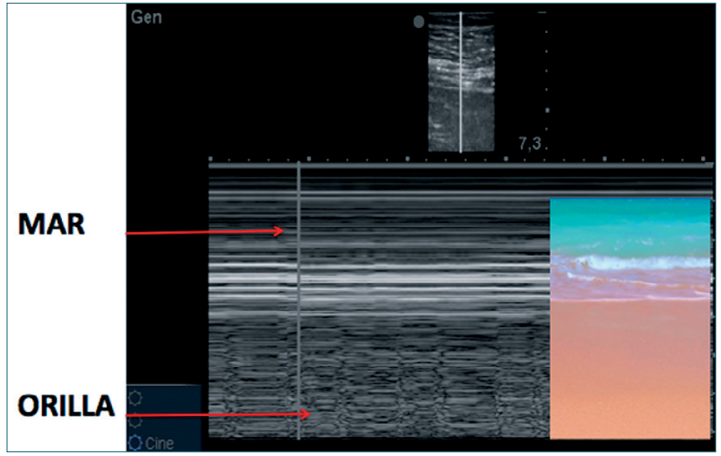

Figura 6. Aplicación de modo M "Signo de la orilla de playa".

nocer lo que representan y en qué entidades se producen, pero a su vez hay que diferenciarlas entre sí para evitar errores de interpretación[7],[8].

Las más importantes son las Líneas A: Líneas hiperecogénicas horizontales y paralelas que se sitúan a una distancia múltiplo de la que existe entre el transductor y la línea pleural.

Si aplicamos el modo $\mathrm{M}$, se distinguen 2 zonas bien diferenciadas, que configuran el signo de la orilla (seashore sign): la parte superior, que corresponde a la pared torácica, formada por líneas horizontales paralelas (el mar), y la parte inferior, desde la pleura, de aspecto granulado, como arena de playa.

El pulmón aireado subyacente a la pleura es una interfase altamente reflectante que bloquea la penetración de los haces de ultrasonidos. El patrón del pulmón normal representa, por tanto, un artefacto por reverberación con múltiples ecos de una intensidad media, de aspecto moteado. La principal caracterís- tica que hay que observar es la presencia de deslizamiento o sliding pleural en la superficie de unión pleuropulmonar, que ocurre obligatoriamente con la insuflación y el vaciado pulmonar durante las fases respiratorias. Otra forma de recordar esta anatomía es el signo de la avestruz (Figura 7), donde se observarán ambas costillas y la línea pleural hiperefringente[9].

En conclusión, el examen normal pulmonar se basa en artefactos, es repetible, con ausencia de radiación y ciertamente fácil de aprender.

\section{Neumotórax}

El ultrasonido es un muy buen método para evaluar la pleura y ha demostrado ser superior a la radiografía de tórax. La detección de neumotórax es especialmente importante en el paciente que presenta disnea. Por ejemplo, luego de un traumatismo torácico, el barotrauma asociado a la ventilación mecánica, tras la cateterización venosa central yugular o subclavia, y en pacientes a los que se va a trasladar en medios aéreos[10],[11].

El transductor más útil es el lineal (Figura 8), pero también puede utilizarse el transductor cardiológico o convexo de frecuencias más bajas. Deben estudiarse cada uno de los cuadrantes del tórax buscando la ausencia del deslizamiento pleural. Sobre todo en los espacios intercostales más altos y de manera bilateral.

La ecografía es muy sensible para el diagnóstico del neumotórax incluso de pequeño tamaño (ocultos en la radiografía de tórax). Diferentes estudios la cifran entre un 90-100\%. Existen varios signos ecográficos. El primero es la ausencia de «deslizamiento pulmonar», ya que la pleura visceral pierde el contacto

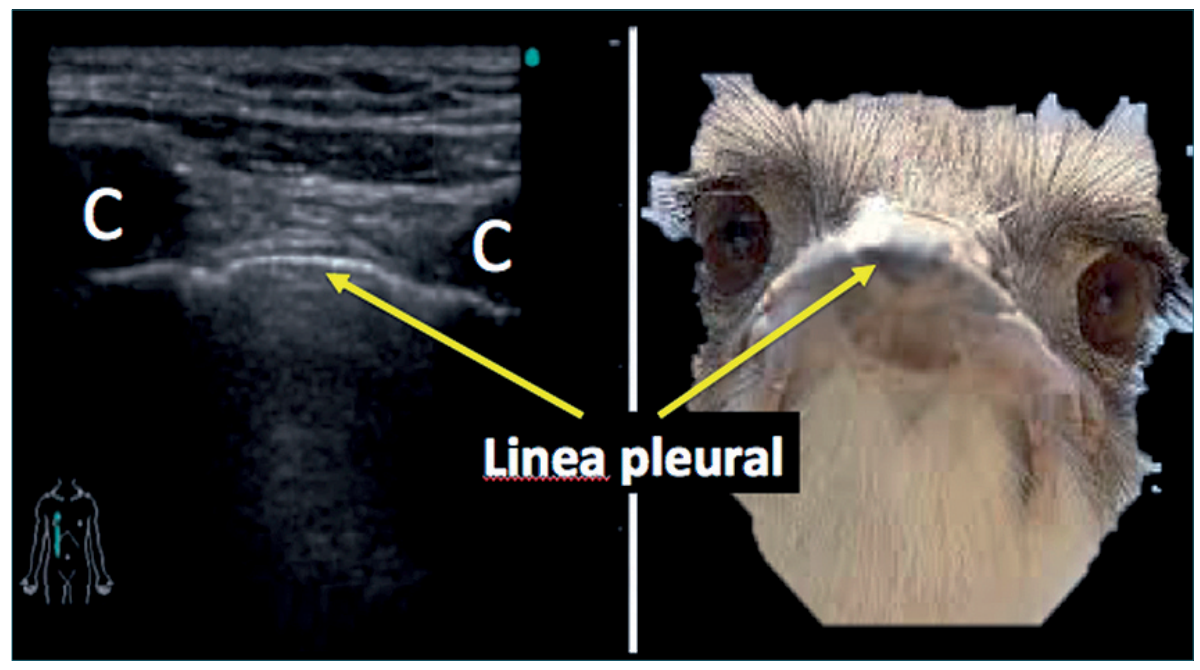

Figura 7. Signo de la avestruz. 


\begin{tabular}{|c|c|}
\hline \multicolumn{2}{|c|}{ Tipos de transductor } \\
\hline \multirow{2}{*}{ FRECUENCIA } & PROFUNDIDAD \\
\hline & $6 \mathrm{~cm}$ \\
\hline $5-8 \mathrm{MHz}$ & $10 \mathrm{~cm}$ \\
\hline $2-5 \mathrm{MHz}$ & $30 \mathrm{~cm}$ \\
\hline $1-5 \mathrm{MHz}$ & $35 \mathrm{~cm}$ \\
\hline
\end{tabular}

Figura 8. Tipo de transductor ideal para detectar neumotórax que corresponde al lineal.

con la pleura parietal. En el modo $\mathrm{M}$ se pierde la apariencia de "orilla de playa» (con arena y mar) y solo se visualizan líneas horizontales paralelas, imagen conocida como el signo de la estratosfera o código de barras. No obstante, la falta de deslizamiento pulmonar, puede producirse en otras enfermedades y circunstancias, como las adherencias pleurales, la intubación bronquial selectiva y la contusión, la consolidación y la atelectasia pulmonares. Esta falta de especificidad hace que la decisión de realizar un tratamiento descompresivo inmediato basado exclusivamente en este signo dependa de las circunstancias clínicas del paciente. En el caso de inestabilidad hemodinámica (incluida la parada cardiocirculatoria), se optaría por la colocación de un drenaje. En el caso de que no existiera compromiso vital urgente, sería recomendable la realización de otra técnica de imagen. Al utilizar modo M (Figura 9) se visualizará la pérdida del signo de orilla de playa y se observará el signo de la estratósfera o código de barras[13].

La presencia de líneas B nos permite descartar un neumotórax, ya que implica la aposición de ambas pleuras, lo que permite que se forme el artefacto.

Por último, existe un signo específico que es el hallazgo del denominado «punto pulmonar» (Figura 10) (lung point). Esta es una interface entre el pulmón aireado y el pulmón sin aire, es difícil de encontrar, pero una vez encontrado su especificidad es de $100 \%$. Se caracteriza porque se produce una sucesión de imágenes normales (arenosas) durante la inspiración y anormales (líneas horizontales) durante la espiración, y se corresponde con el punto del tórax donde, en inspiración, el pulmón «toca» o alcanza a la pared torácica en el seno de un neumotórax no masivo.

Es decir, corresponde al límite entre neumotórax

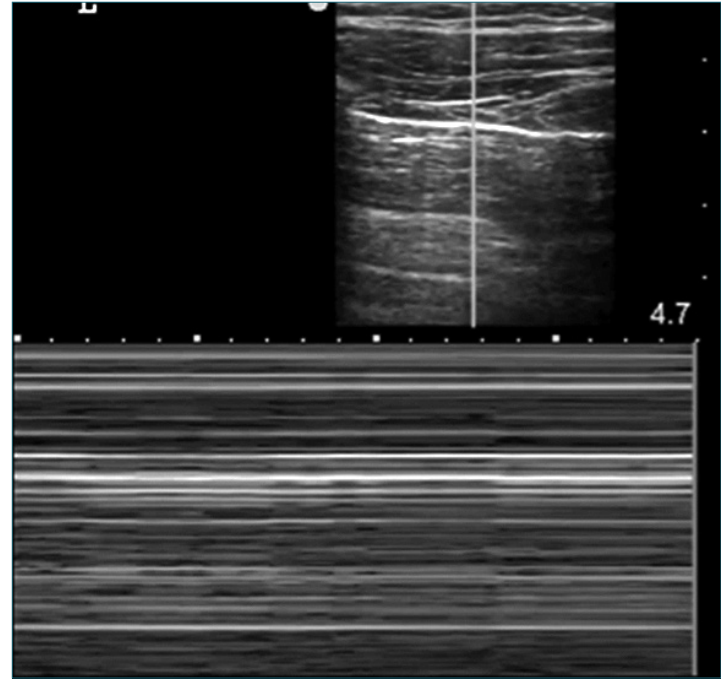

Figura 9. Signo del código de barras.

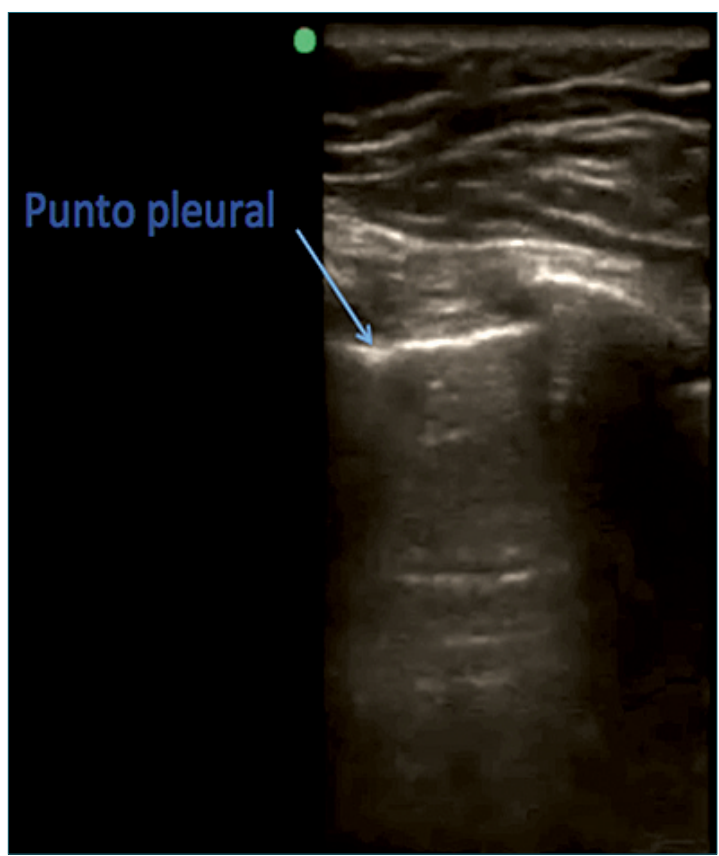

Figura 10. Signo del punto pleural que tiene un $100 \%$ de especificidad de neumotórax.

y pulmón normal como se observa en la imagen de la tomografía computarizada.

Lichtenstein, quien es considerado el padre del ultrasonido pulmonar, diseñó un protocolo de manejo, ya muy difundido, el protocolo BLUE (bedside lung 


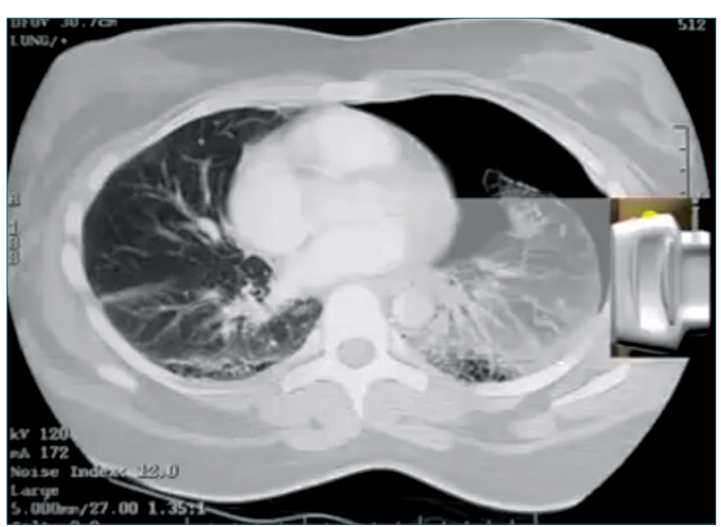

Figura 11. Tomografía de tórax que demuestra el lugar del punto pleural.

ultrasound in emergency) (Figura 12) evalúa como primer punto la presencia de deslizamiento pleural, como se ve en la siguiente (Figura 12)[14],[15].

Existen eventuales falsos positivos en que no se observe deslizamiento pleural y estos pueden ser:

1. Intubación monobronquial.

2. Enfermedad pulmonar crónica (fibrosis pulmonar).

3. Injuria pulmonar aguda.

4. Antecedente de pleurodescis.

\section{Neumotórax luego de una punción venosa cen-} tral

Es importante explicar que la punción venosa central es uno de los procedimientos que con mayor frecuencia se realizan en paciente crítico y en quirófano. Esta es una técnica que tiene una incidencia de complicaciones que varían entre un 1 a 15\%. Luego de una punción venosa central realizada a nivel yugular o

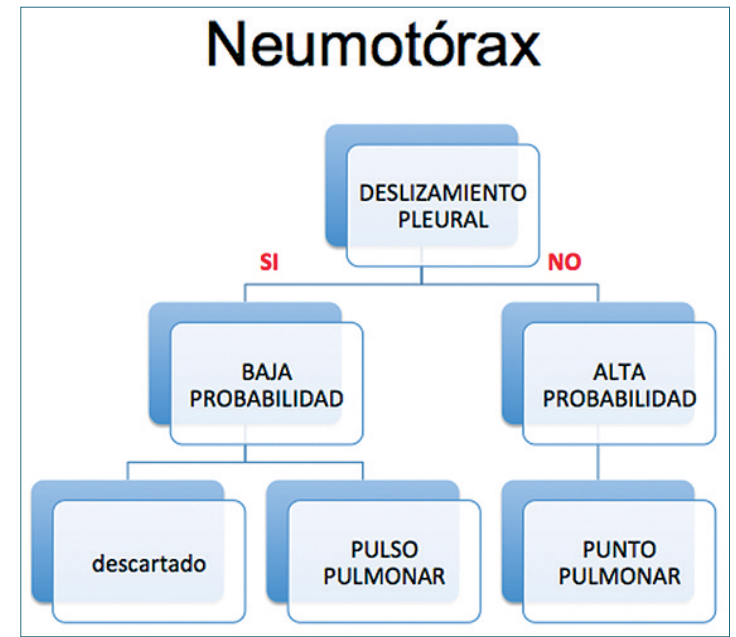

Figura 12. Esquema para el manejo de un neumotórax.

subclavio está el riesgo de punción pleural inadvertida y por ende de neumotórax. Existen variantes anatómicas donde la arteria carótida no se encuentra en su posición habitual, como se muestra en la Figura 13.

Con el uso de US para realizar la punción venosa central, la incidencia de neumotórax disminuyó de un $3,5 \%$ a menos de un $1 \%[16]$.

\section{Conclusión}

El US pulmonar es una técnica sensible y específica a la hora de diagnosticar neumotórax.

Esto permitirá cambiar conductas y manejo, evitando llegar a un neumotórax a tensión.

Pero, lo más relevante es que se trata de una técnica amistosa y fácil de aprender.

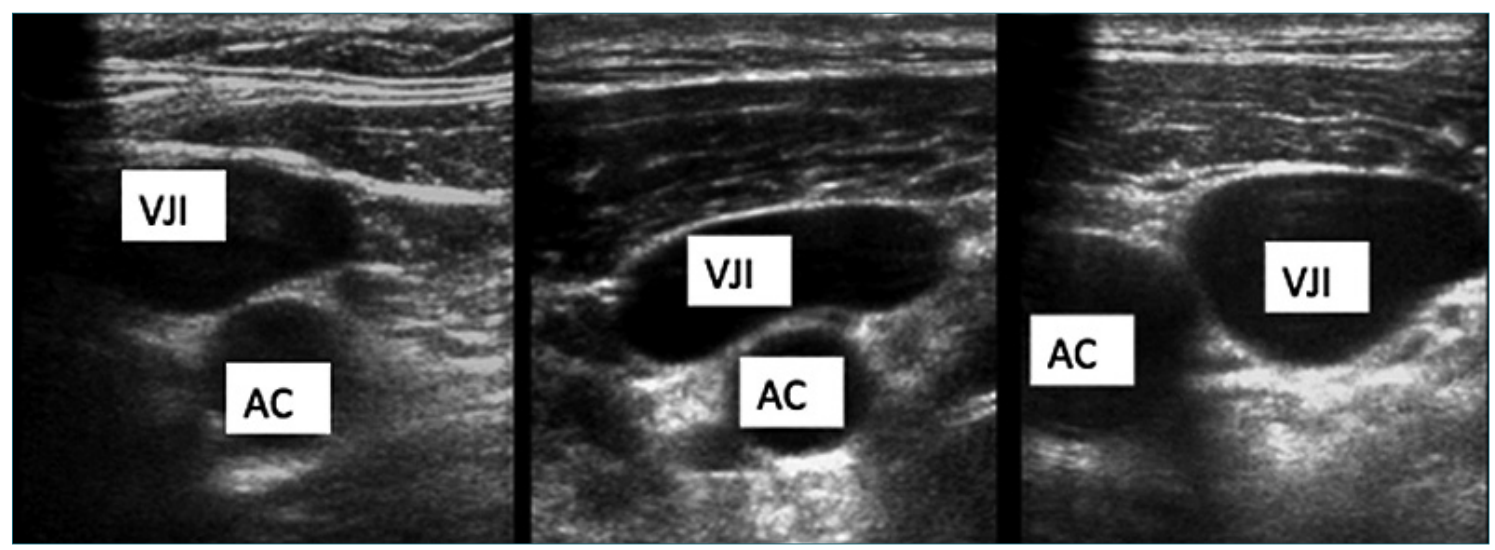

Figura 13. Diferentes ubicaciones anatómicas de la vena yugular interna ( $\mathrm{VJ}=$ vena yugular interna; $\mathrm{AC}=$ arteria carótida). 


\section{Referencias}

1. Miller A. Practical approach to lung ultrasound. BJA Educ. 2016;16(2):39-45. https://doi. org/10.1093/bjaceaccp/mkv012

2. Colmenero M, García-Delgado M, Navarrete I, López-Milena

G. Utilidad de la ecografía pulmonar en la unidad de cuidados intensivos. Med Intensiva. 2010;34(9):620-8. https://doi.org/10.1016/j.medin.2010.04.004

3. Zieleskiewicz L, Muller L, Lakhal $K$. Point of care ultrasound in intensive care units. Intensive Care Med. 2015;41:1638-47. https://doi.org/10.1007/s00134015-3952-5 PMID:26160727

4. Lichtenstein DA. Lung ultrasound in the critically ill. Ann Intensive Care. 2014 Jan;4(1):1-8. https:// doi.org/10.1186/2110-5820-4-1 PMID:24401163

5. Xirouchaki N, Kondili E, Prinianakis G, Malliotakis P, Georgopoulos D. Impact of lung ultrasound on clinical decision making in critically ill patients. Intensive Care Med. 2014 Jan;40(1):57-65. https://doi. org/10.1007/s00134-013-31333 PMID:24158410

6. Volpicelli $G$, Elbarbary $M$, Blaivas $M$, Lichtenstein DA, Mathis G, Kirkpatrick AW, et al.; International Liaison Committee on Lung Ultrasound (ILC-LUS) for International Consensus Conference on Lung Ultrasound
(ICC-LUS). International evidence-based recommendations for point-of-care lung ultrasound. Intensive Care Med. 2012 Apr;38(4):577-91. https://doi. org/10.1007/s00134-012-25134 PMID:22392031

7. Gargani L, Volpicelli G. How I do it: lung ultrasound. Cardiovasc Ultrasound. 2014 Jul;12(1):25-30. https://doi. org/10.1186/1476-7120-12-25 PMID:24993976

8. Aras MA, Teerlink JR. Lung ultrasound: a 'B-line' to the prediction of decompensated heart failure. Eur Heart J. 2016 Apr;37(15):1252-4. https://doi. org/10.1093/eurheartj/ehw094 PMID:27080198

9. Cortellaro F, Ceriani E, Spinelli M, Campanella C, Bossi I, Coen $D$, et al. Lung ultrasound for monitoring cardiogenic pulmonary edema. Intern Emerg Med. 2017 Oct;12(7):1011-7. https://doi. org/10.1007/s11739-016-1510-y PMID:27473425

10. Wongwaisayawan $S$, Suwannanon R, Sawatmongkorngul S, Kaewlai R. Emergency Thoracic US: the essentials. Radiographics. 2016 May-Jun;36(3):640-59. https://doi.org/10.1148/ rg.2016150064 PMID:27035835

11. Lichtenstein DA. BLUE-protocol and FALLS-protocol: two applications of lung ultrasound in the critically ill. Chest. 2015 Jun;147(6):1659-70. https:// doi.org/10.1378/chest.14-1313
PMID:26033127

12. Lichtenstein D, Meziere G. Biderman. The "lung point": an ultrasound specific sign of pneumothorax. Intensive Care Med. 2000;26:1434-40. https://doi. org/10.1007/s001340000627 PMID:11126253

13. Lichtenstein DA, Lascols $N$, Mezière G, Gepner A. Ultrasound diagnosis of alveolar consolidation in the critically ill. Intensive Care Med. 2004 Feb;30(2):276-81. https://doi. org/10.1007/s00134-003-20756 PMID: 14722643

14. Piccoli M, Trombaiolo P, Solustri $A$, et al. Bedside and follow-uo of patients with pleural effusion. Chest. 2005;128:3413-20. https://doi. org/10.1378/chest.128.5.3413 PMID: 16304293

15. Jambrik Z, Monti S, Coppola V, Agricola E, Mottola G, Miniati $M$, et al. Usefulness of ultrasound lung comets as a nonradiologic sign of extravascular lung water. Am J Cardiol. 2004 May;93(10):1265-70. https://doi.org/10.1016/j. amjcard.2004.02.012 PMID:15135701

16. Worku B, Gulkarov I, Girardi LN, Salemi A. Pulmonary embolectomy in the treatment of submassive and massive pulmonary embolism. Cardiology. 2014;129(2):106-10. https:// doi.org/10.1159/000363647 PMID:25227239 